\title{
HaBilid ADES DE AUTO PROTEÇÃo ACERCA do ABUSO SEXUAL EM MULHERES COM DEFICIÊNCIA MENTAL
}

\author{
Sexual abuse Self protective SKILls in Women With metal Retardation
}

\author{
Roberta Dias de BARROS ${ }^{1}$ \\ Lúcia Cavalcanti de Albulquerque WILLIAMS² \\ Rachel de Faria BRIN O ${ }^{3}$
}

\begin{abstract}
RESUM 0: tendo em vista o crescente número de casos de abuso sexual que vêm sendo denunciados e a vulnerabilidade de algumas populações específicas, como por exemplo, a população de pessoas com Necessidades Educacionais Especiais, mais especificamente os deficientes mentais, esse estudo teve como objetivo caracterizar as habilidades de proteção contra o abuso sexual desses indivíduos. Para isso, foi real izada uma entrevista estruturada, que consistiu em um instrumento traduzido "What If Situation Test"( Teste de Situações "E Se"), com seis mulheres com idades entre 18 e 50 anos. Pôde-se perceber pela análise dos resultados que as participantes não tinham um repertório de habilidades de auto proteção adequado para se protegerem em situações potencialmenteabusivas do ponto de vista sexual. Deacordo com os dados obtidos, as participantes foram capazes de discriminar as situações apropriadas das situações inapropriadas, ou seja, el as reconheceram quais situações Ihes colocam em risco de sofrer abuso sexual. Em contrapartida, elas não foram capazes de se retirar de uma situação inapropriada e não reportaram tal situação a pessoas de confiança, o que justifica afirmar que el as apresentam um déficit em seu repertório de habilidades de auto proteção. Esse estudo apóia a literatura ao confirmar que essa é uma população vulnerável em relação ao abuso sexual e permite ampliar a discussão sobre a necessidade de programas de prevenção para a mesma.
\end{abstract}

PALAVRAS-CHAVE: abuso sexual; deficiência mental; educação para prevenção; educação especial.

A BSTRACT: considering the increasing number of reported sexual abuse cases and the vulnerability of some specific populations, such as persons with special needs, more specifically people with mental retardation, this study intended to characterize self protection against sexual abuse skills for the latter. With this purpose, a translated structured interview "What if Situation Test" was applied in six special school in the city of São Carlos, Brazil, with students aged between 18-50 years old. Results showed that this study's participants did not havean appropriate repertoire of self protection skills to protect themselves from potential sexually abusive situations. Data showed that the participants were able to distinguish between appropriate and inappropriate situations, which means that they recognized situations that offered risks. However, they were not able to leave an inappropriate situation and report it to someone they trusted, which may be indicative of deficit in their self protection skills' repertoire. This study supports the existing literature, confirming this population's vulnerability concerning sexual abuse and contributes to a wider discussion about sexual abuse preventive programs.

KEYWORDS: sexual abuse, mental retardation, education for prevention; special education.

\footnotetext{
${ }^{1}$ Aluna do Programa de Pós-graduação em Educação Especial da Universidade Federal de São Carlos robarros@hotmail.com

${ }^{2}$ Profa Titular do Departamento de Psicologia da Universidade Federal de São Carlos williams@power.ufscar.br

${ }^{3}$ Profa A djunta do Departamento de Medicina da Universidade Federal de São Carlos brino@power.ufscar.br.
} 


\section{INTRODUÇÃO}

A relação sexual entre adultos e crianças é uma prática realizada há muitos anos, no entanto, atéa década de 50 este assunto ainda era considerado um tabu enada se discutia sobre suas conseqüências (BLAN CHARD, 1996). Cabe aqui ressaltar que o abuso sexual é um ato condenado pela justiça, ou seja, é um crime e deve ser tratado como tal, de maneira que o agressor seja punido e que a vítima receba o encaminhamento necessário para não ter os danos agravados. A tualmente, o assunto édiscutido tanto nos meios de comunicação quanto no meio acadêmico, sendo que a mídia, por vezes, aborda esse assunto de maneira sensacionalista. $O$ meio acadêmico busca compreender os fatores que desencadeiam a violência sexual, por meio de pesquisas, procurando estudar manei ras mais eficazes de evitar com que ela ocorra. No entanto, é importante tanto nos meios de comunicação quanto dentre aqueles que fazem parte da academia, que se unam esforços para que esse tema seja colocado em evidência de forma que, cada vez mais, os casos de abuso sejam denunciados.

Parece importante para se prevenir abusos sexuais contra crianças que a temática seja amplamente discutida, pesquisada e divulgadas informações acerca do que defineabuso sexual, decomo identificá-lo, que conseqüências traz à criança e à família, para quem e quando notificar suspeitas de ocorrência, de forma a instrumentalizar a comunidade em geral para enfrentar essa problemática tão freqüente e muitas vezes inacessível aos órgãos de proteção à criança. Assim, a população em geral terá conhecimentos suficientes que podem auxiliar na luta contra essa prática abusiva, por meio da prevenção.

Dentre todos os tipos de violência que as pessoas podem sofrer, considera-se violência sexual o abuso de poder, no qual o indivíduo éusado para gratificação sexual de outro indivíduo, através da indução a práticas sexuais, com ou sem violência física. (MINISTÉRIO DA SAÚDE, 2007). Tendo em vista que o abuso sexual é um crime que infringe os direitos de crianças e adol escentes e que pode causar prejuízos cognitivos e emocionais nos indivíduos, este tema deve ser tratado com muito empenho e a devida seriedade para que ações de caráter preventivo estejam cada vez mais presentes em nossa sociedade. Habigzang e Caminha (2004, p.21) afirmam que o termo abuso contra crianças e adolescentes:

[...] é usado para englobar a negligência, bem como a violência psicológica, física e sexual, de maneira repetida e intencional, perpetrado por um adulto ou al guém em estágio de desenvolvimento superior (idade, força física, posição social, condição econômica, inteligência, autoridade).

Para os autores citados acima, o agressor utiliza do poder, da relação de confiança e/ ou força física para colocar a criança e/ ou adolescenteem situações que envolvem comportamentos sexuais, para as quais não possui condições maturacionais biológicas e psicológicas de enfrentamento. 
Segundo Gabel, (1997) e Watson (1994), nas situações deabuso devem estar presentes a intenção ea premeditação. Deacordo com Habigzang eCaminha (2004), supõe-se que devem ser observados três fatores para que haja distinção entre atos abusivos e não abusivos, descritos a seguir:

[...] o poder exercido pel o grande sobre o pequeno, a confiança que o pequeno (dependente) tem no grande (protetor) e o uso delinqüente da sexualidade atentado ao direito que o indivíduo tem de propriedade sobre seu próprio corpo (HABIGZANG; CAMINHA, 2004, p. 28).

Há países que consideram que deve haver uma diferença de idade de no mínimo cinco anos entre a vítima e o agressor. De acordo com a legislação canadense, por exemplo, crianças menores de 12 anos nunca são consideradas capazes de consentir atividades sexuais e crianças entre 12 e 14 anos, também, são consideradas incapazes de consentir atos sexuais, exceto sob circunstâncias específicas envolvendo atividades sexuais com seus pares (diferença de três anos). De acordo com o artigo 224 do Código Penal Brasileiro, crianças menores de 14 anos de idade não têm possibilidade de consentir, assim como um indivíduo alienado ou deficiente mental, ou aquele que por qualquer outra causa não pode oferecer resistência. No entanto, a legislação brasileira não oferece informações sobre a diferença de idade entre a vítima e o agressor.

A diferença de idade não envolve uma questão de conservadorismo, mas sim da rel ação de desequilíbrio das relações de poder inerentes à defini ção de violência (WILLIAMS, 2002). Entretanto, há consenso que quando houver uso de força, ameaça ou exploração da autoridade da criança, independentemente da idade, deve-se responsabilizar o adulto pelo comportamento abusivo (AMAZA RRAY; KOLLER, 1998; COHEN; MAN NARINO, 2000; CLOITRE, et al., 2002; HAYDE; BENTOVIM; MON CK, 1995; ZAVASCHI et al., 1991).

Os estudos mostram que, em grande parte dos casos de abuso sexual, o agressor é uma pessoa próxima, que tem o carinho e a confiança da criança e que, muitas vezes, desempenha papel decuidador da vítima (BRAUN, 2002; CAMINHA, 2000; KAPLAN; SADOCK; GREBB, 1997). Muitas vezes há inclusive uma relação familiar entre eles, podendo ser pai, padrasto, tio, irmão ou algum conhecido da família. Os dados de um levantamento de 30 casos notificados na Delegacia da Mulher, realizado por Brino e Williams (2003) na cidade de São Carlos, mostraram que, em $10 \%$ dos casos, o pai era o agressor, o padrasto em $23,4 \%$ dos casos, o tio eo irmão em $3,3 \%$ dos casos cada um, o vizinho em $26,6 \%$ dos casos. Por outro lado, dentreos casos, apenas 33,4\% destes tinham como agressor uma pessoa desconhecida.

Em um estudo realizado por Drezett (2000) no Hospital Pérola Byington deSão Paulo, de 1.200 casos de violência sexual documentados no ano de 2000, em $84,5 \%$ dos casos, o agressor era conhecido da vítima. O pai era o agressor em $21,7 \%$ dos casos, o padrasto em $16,7 \%$, o pai adotivo em $1,6 \%$, o tio em $11,6 \%$, o avô em $10 \%$, o vizinho em $16,7 \%$ e outro conhecido da família em $21,7 \%$. 
Saffioti (1996) constatou que nos casos de abuso intrafamiliar em 69,9\% das vezes o pai biológico era o agressor, em $29,8 \%$ o padrasto e em 0,65 dos casos o pai adotivo. O vínculo entrea vítima eo agressor éum dos fatores que mais agrava as conseqüências do abuso em relação ao desenvolvimento cognitivo eemocional da criança e do adolescente, uma vez que este abal a sua estrutura familiar, a qual deveria ser a estrutura de base para que qualquer indivíduo desenvolva seu repertório básico de comportamentos.

A lém disto, devido à relação de afeto entre a vítima e o agressor é mais difícil para a vítima procurar ajuda. Ela geralmentesemantém caladae, muitas vezes, seculpa esentevergonha pelo queaconteceu, acabando por ficar resignada. Deacordo com Saffioti (1996), a violência, que geralmente ocorre dentro de casa, permanece silenciosa. Desta maneira, não se pode conhecer a verdadeira realidade da ocorrência de abuso sexual, ou seja, muitos casos não devem ser relatados pela vítima. A inda, "a posição deconfiança na qual os agressores seencontram, assi m como a posição indefesa da criança na família, torna mais fácil encobrir o crimeepersuadir ou assustar a criança para que esta se mantenha calada" (ABRAPIA,2002, p. 4).

De acordo com Brown et al. (1998), podem-se definir al gumas classes devariáveis associadas ao risco deabuso sexual. Dentreelas destacam-se: variáveis demográficas (juventude da mãe ou morte do pai), relações intrafamiliares (sociopatia materna, eventos de vida negativos, presença de padrasto, punições severas), características dos pais (gravidez indesejada) e características da criança (sexo feminino, portadora de deficiência). Para Padilha (2002), os indivíduos mais expostos ao risco de abuso são aqueles cujas famílias ou membros destas não discriminam situações instáveis ou potencialmente perigosas. Deacordo com estas idéias, os deficientes mentais podem ter um risco maior do que as pessoas sem deficiência (LUMLEY; MILTEN BERGER, 1997; WILLIAMS, 2003).

Algumas estatísticas norte-americanas confirmam a vulnerabilidade dos portadores deNEEs (N ecessidades Educacionais Especiais), pois mostram que estes são vítimas em maiores proporções do queas pessoas da população em geral (STRICKLER, 2001; SOBSEY et al., 1994; A M MERMAN; VAN HASSELT; HERSEN, 1988). O aumento de risco da pessoa com deficiência mental pode ser explicado por nove fatores enumerados conforme aponta Strickler (2001): a) aumento de dependência deoutras pessoas para cuidados a longo prazo; b) negação de direitos humanos, resultando em uma percepção de ausência de poder tanto pela vitima quanto pelo agressor; c) percepção de menor risco de ser descoberto por parte do agressor; d) dificuldades da vitima em fazer com que os outros acreditem em seus relatos; e) menor conhecimento por parte da vítima do que é adequado ou inadequado em termos de sexualidade; $f$ ) isolamento social, aumento do risco de ser manipulado por outros; g) potencial para desamparo e vulnerabilidade em locais públicos; h) valores eatitudes mantidos por profissionais na área deeducação especial em relação à inclusão, sem considerar a capacidade do indivíduo de auto proteção ei) falta de independência econômica por parteda maioria dos indivíduos portadores de deficiência mental. 
Um estudo realizado por Sullivan e Knutson (2000) identificou que crianças portadoras de NEEs têm 3.4 vezes mais chances de sofrerem negl igência e serem física, emocional ou sexual mente abusadas quando comparadas às crianças não portadoras. Além disso, os autores constataram quecrianças com dificuldades de comunicação têm o risco cinco vezes maior para negligência e abuso físico e três vezes maior para abuso sexual.

Segundo Williams (2003, p. 142):

O indivíduo portador de deficiência de qualquer modalidade - seja visual, auditiva, física ou mental - encontra-se em uma posição de grande vulnerabilidade em relação ao não portador, sendo freqüentemente marcante a assimetria das relações de poder na interação entre ambos. Tal assimetria de rel ação hierárquica é multiplicada, conforme a severidade de cada caso, sendo ampliada se o portador de necessi dades especiais pertencer a um outro grupo de risco, como por exemplo, se for mulher ou crianças.

Em se tratando particularmente do abuso sexual, a mulher portadora de deficiência mental sofre maiores riscos devido a alguns fatores como: dificuldades no julgamento eem habilidades sociais, dificul dades de comunicação, inabilidade para buscar ajuda e para denunciar o abuso, falta de conhecimento sobre o comportamento sexual apropriado e dependência excessiva a outros e atitude de aceitação a pedidos fortemente instalada, o que, infelizmente, pode generalizar para solicitações de abuso (LUMLEY et al., 1998).

Em um estudo realizado no período entre 2001 e2003, dentre todos os casos de abuso sexual registrados na Delegacia da Mulher da cidade de São Carlos, $10 \%$ tinham como vítimas mulheres com deficiência. Dentreessas, $80 \%$ das vítimas eram deficientes mentais e $20 \%$ apresentavam deficiência auditiva. N esses casos, todas as vítimas eram do sexo feminino e suas idades variaram entre 10 e 38 anos. Em relação ao vínculo entre a vítima e o agressor, duas vítimas eram namoradas, uma era neta, uma era vizinha e uma era amiga (MONTONI, 2004).

No entanto, a experiência clínica do Laboratório de Anál ise ePrevenção à Violência (LAPREV), da Universidade Federal de São Carlos, mostra que há casos deabuso sexual queenvolvemeninos portadores dedeficiência mental. A literatura não apresenta dados que corroborem para essa informação, daí a necessidade de realizar futuros estudos inclusive com meninos.

A valiar as situações de risco em queas pessoas seencontraméessencial para que possam ser planejadas estratégias de prevenção em seus três níveis (primária, secundária eterciária), assim como postula Wolfe (1998). Pode-seevitar que o abuso ocorra ou que el e se repita por meio de programas educacionais para crianças e/ ou adolescentes efamílias (prevenção primária e/ ou secundária ), podese facilitar para que as vítimas relatem o abuso sofrido ou facilitar seu acesso às instituições e aos profissionais que possam ajudar a minimizar o estresse próprio da situação (prevenção secundária) em de programas de capacitação de 
profissionais eainda, pode-se minimizar o impacto do abuso no desenvolvimento da vítima (prevenção terciária) pelo tratamento desta e de sua família.

Consi derando-se os fatores de risco citados e considerando ainda que no artigo 70 do ECA “édever detodos prevenir a ocorrência deameaça ou violação dos direitos da criança edo adolescente" (p.33), éque se fundamenta a necessidade de estudos destinados ao treinamento de habilidades preventivas para crianças e pessoas vulneráveis como as que têm defi ciência mental. No caso do abuso sexual, o foco da prevenção consiste em alterar o conhecimento e as habilidades dos indivíduos por meio de grupos de instrução de segurança pessoal (WURTELE; HUGHES; OWENS, 1998). Em se tratando de indivíduos que apresentam atraso mental, o abuso sexual pode ocorrer em diversos ambientes como instituições e centros comunitários, envolvendo cuidadores, provedores, membros da família e pares com NEEs (BEAIL et al. apud TANG; LEE, 1999).

Alguns pesquisadores dos EUA desenvolveram programas de intervenção com tal propósito, mas há poucos dados em relação à eficácia destes (LUMLEY et al., 1998). Lumley et al. (1998) demonstraram que mulheres com retardo mental de leve a moderado podem adquirir habilidades de auto proteção em relação ao abuso sexual, podendo demonstrar tais habilidades em situações de role-play (dramatização de papéis). No entanto, a generalização destas habilidades não pôde ser demonstrada nesse mesmo estudo, ou seja, as avaliações de role-play não foram suficientes para determinar se tais habilidades seriam executadas em uma situação real.

Um estudo conseqüente apontou resultados que corroboram para a constatação de que ainda é vaga a noção sobre se as habilidades desenvolvidas durante o programa de intervenção podem ou não ser general izadas e mantidas no ambiente natural (MILTENBERGER et al., 1999). Os autores salientam a importância de aval iações naturalísticas de habilidades de auto proteção de abuso sexual e treinamento in situ para ensinar tais habilidades, para que os programas de treinamento sejam efetivos. As situações naturais são situações do dia a dia em que as mulheres estão expostas aos agressores, podendo ser em situações de trabal ho, na escola, no médico, em casa, etc.

De acordo com a literatura, consideram-se as habilidades de auto proteção aquel as que empoderam o indivíduo para que ele seja capaz de, diante de situações de risco, apresentar comportamentos adequados que o protejam de possíveis maus tratos, inclusive de abuso sexual. Podem ser citadas habilidades assertivas tais como um grito de autodefesa, pedido de ajuda para amigos econtar para al guém caso al gum inci dente ocorra (HÉBERT et al., 2001). Wurtele; Hughes eOwens (1998) consideram como habilidades que devem ser treinadas efortal ecidas em programas escolares: reconhecer, resistir e reportar agressões sexuais.

A ntes de realizar intervenções com indivíduos que apresentam atraso mental, parece importante que sejam levantadas as necessidades, limitações e potencialidades em relação ao seu repertório de habilidades auto protetoras, para 
queas atividades sejam adaptadas a tais condiçõese, dessa maneira a probabilidade de sucesso dessas seja a maior possível.

Pode-se questionar se os indivíduos com e sem atraso mental apresentam habilidades de auto proteção e se há diferenças entre seus repertórios que possam ser atribuídas ao atraso. Assim, o presente estudo teve como objetivo caracterizar o repertório de habilidades de auto proteção em mulheres com deficiência mental, por meio de um teste projetivo de situações.

\section{Método}

\section{Participantes}

Participaram do estudo seis mulheres com idades entre 18 e 50 anos, com deficiência mental diagnosticada. As participantes foram recrutadas por meio do diagnóstico de deficiência mental descrito em seus prontuários na escola especial izada que freqüentavam.

Local

Salas de aula de Escolas de Educação Especial de um município do interior paulista.

\section{Instrumentos}

Utilizou-se um instrumento que foi traduzido para o português pela primeira autora, com autorização da autora do instrumento original. O "What Is Situation Test" - WIST (WURTELE; HUGHES; OWENS,1998) traduzido como Teste deSituações "E se", foi desenvolvido para medir a habilidade decrianças pequenas em reconhecer, resistir e reportar o abuso sexual.

$\mathrm{O}$ instrumento consta de seis vinhetas descrevendo pedidos apropriados einapropriados para ol har ou tocar a genitália das participantes. Essas são instruídas a se imaginar em cada situação e, em seguida, Ihes são feitas cinco questões para determi nar suas habilidades para reconhecer seos pedidos quel hes foram feitos são apropriados ou não, assim como para determinar sua capacidade de usar habilidades de auto proteção, se elas existirem. Consideram-se pedidos apropriados aqueles que não colocam a participante em risco de abuso sexual e esses exemplos podem ser vistos nas situações I, II eVI. A situação I, era a seguinte: "se você caísse de bicicleta, estaria tudo bem se seus pais ol harem suas partes íntimas?". A situação II perguntava se: "após a queda de bicicleta estaria tudo bem se um médico tocasse suas partes íntimas?". E finalmente, dentre as situações apropriadas a sexta situação pergunta se: "estaria tudo bem uma enfermeira, que ajuda o médico, tocasse suas partes íntimas?". 
As outras situações, III, IV e V, são as situações consideradas inapropriadas, ou seja, que colocam a participante em risco de abuso sexual. A situação III descrevia a cena "e se um vizinho, que é uma pessoa mais velha, Ihe dissesse: Ei, (nome da pessoa), vamos brincar de um jogo divertido! Você tira suas roupas eeu vou tirar fotos desuas partes íntimas com a minha câmera!". N a situação IV, descreveu-se a cena: "E se você tivesse uma babá que lhe dissesse: (nome da pessoa), eu vou deixar você ficar acordado até tarde para assistir seu programa favorito na TV sevocêtocar um pouco nas minhas partes íntimas por um tempinho". A última situação inapropriada, a situação $V$, é a seguinte: "E se você estivesse brincando no parqueeum homem quevocêgosta dissesse: Ei, (nome da pessoa), eu Ihecompro um sorvete se vocêtirar as cal ças e medeixar tocar suas partes íntimas".

A pós uma breve descrição da situação, a primeira pergunta feita à participante é se estaria tudo bem aquela situação ocorrer. Ela pode responder sim, não ou não sei. Caso ela responda sim, em qualquer uma das situações, devese seguir para a próxima situação. Caso a resposta seja não ou não sei, dentro da mesma situação devem-se fazer outras quatro perguntas que são: o que a participante diria para a pessoa envolvida na situação, o queela faria diante daquela situação, se ela contaria ou não o queaconteceu para al guém, esesim, quem seria(m) essa(s) pessoa(s).

\section{Procedimentos}

Em um primeiro momento o projeto foi submetido ao Comitê deÉtica em pesquisa com Seres Humanos e recebeu o parecer favorável.

A escola selecionou catorze mulheres com diagnóstico de deficiência mental, para cujas responsáveis foram enviados os Termos deConsentimento LivreeEsclarecido. Dentre essas, onze devolveram os termos assinados por seus responsáveis, sendo que sete responsáveis consentiram a participação e quatro não. Nenhum dos responsáveis que recusou a partici pação na pesquisa justificou sua recusa. Dentre as sete que tiveram o consentimento, a entrevista foi realizada com seis participantes, pois uma das participantes, no dia da realização da entrevista, recusou-se a permanecer na sala.

A pós o contato com a escola para estipular os mel hores horários para a realização da entrevista que não atrapalhassem as atividades das mulheres , realizaram-se as entrevistas na própria escola, em salas de aula, onde ficavam apenas a primeira autora ea aluna. A pós um breverapport, a pesquisadora explicou o objetivo da entrevista, pediu o consentimento da própria participantepara realizála e explicou que se em algum momento a participante quisesse interromper a entrevista, isso seria possível. Nenhuma das participantes se recusou a responder etampouco pediu para interromper a entrevista antes determiná-la. A s entrevistas tiveram duração máxima de 30 minutos. 
A análise dos dados foi quantitativa. De acordo com o WIST, a pontuação máxima que uma participantepoderia ter correspondea 27 pontos para cada resposta correta em três situações inapropriadas e três pontos em situações apropriadas, ou seja, dentre as três situações que são consideradas inapropriadas a participante que tivesse 27 pontos seria considerada como tendo um repertório de habilidades de auto proteção ad equado e, dentre as três situações apropriadas, a pontuação máxima que indica que a participante discrimina situações não abusivas seria de 3 pontos.

\section{RESULTADOS}

A análise dos dados obtidos com as entrevistas foi feita considerando que a pontuação máxima de 3 pontos dentre as situações apropriadas (I, II e VI) é indicativa de que a participante sabe discriminar situações que não Ihe oferecem risco de sofrer abuso sexual, e que a pontuação máxima de 27 pontos dentre as situações inapropriadas (III, IV e V) é indicativa de que a participante tem um repertório de habilidades adequado para se proteger diante de situações abusivas do ponto de vista sexual.

Conforme mostra a Tabela 1, cada participante recebeu uma pontuação de acordo com suas respostas.

Tabela 1 - Pontuação de cada participante no WIST em situações apropriadas e inapropriadas.

\begin{tabular}{ccc}
\hline Participante & $\begin{array}{c}\text { Pontuação em Situações } \\
\text { Apropriadas }\end{array}$ & $\begin{array}{c}\text { Pontuação em Situações } \\
\text { Inapropriadas }\end{array}$ \\
\hline P1 & $3 / 3$ & $15 / 27(55,5 \%)$ \\
P2 & $3 / 3$ & $13 / 27(48,14 \%)$ \\
P3 & $3 / 3$ & $14 / 27(51,85 \%)$ \\
P4 & $3 / 3$ & $14 / 27(51,85 \%)$ \\
P5 & $3 / 3$ & $4 / 27(14,81 \%)$ \\
P6 & $2 / 3$ & $3 / 27(11,11 \%)$ \\
\hline
\end{tabular}

Tais dados representam a pontuação que as participantes tiveram em todas as situações. No que se refere às situações apropriadas, pode-se concluir que todas as partici pantes souberam discriminar quando uma situação não Ihes oferecia risco de abuso sexual. A penas uma (P6), dentre as seis participantes, não obtevea pontuação máxima, ou seja, dentre as três situações apropriadas, ela reconheceu apenas duas.

Em relação às situações inapropriadas, a maior pontuação foi de 15 pontos (P1). Isso significa que essa participante possuía 55,5\%, do repertório adequado de habilidades de auto proteção. Dentre as situações inapropriadas, a participante que apresentou menor pontuação obteve 3 pontos (P6) dentre os 27 possíveis, ou seja, essa participanteapresentava apenas $11,11 \%$ do repertório de habilidades adequado para se proteger diante de uma situação potencial mente abusiva do ponto de vista sexual. 
De acordo com o WIST, podem-se anal isar os resultados, conforme se segue: para cada pergunta em cada uma das situações há al gumas possi bilidades de respostas que caracterizam a pontuação:

Na primeira pergunta: "estaria tudo bem?", consi deram-seas respostas sim, não e não sei.

Em relação à pergunta seguinte, "o que você diria" considera-se uma recusa definitiva quando a pessoa recusa definitivamente concordar com o pedido. Reconhece a inapropriação do pedido. As declarações precisam seguir as regras de segurança. Considera-se uma recusa cautelosa quando a pessoa recusa cautelosamente concordar com os pedidos com ameaças, descul pas ou adiamentos. Final mente, é consi derado não recusa quando a pessoa não recusa o pedido, não sabe o que falar, ou concorda com o pedido. A criança dá uma resposta comportamental.

Na terceira pergunta, "o que você faria" quando a pessoa imediatamentese retira da situação, considera-seuma recusa/ fuga definitiva. Sea pessoa descreve uma fuga atrasada, que não interrompe imediatamente com a situação. Considera-se recusa/ fuga vaga. E por fim, se a pessoa permanece na situação ou age de acordo com o pedido, dá uma resposta agressiva ou apenas dá uma resposta verbal, considera-se não recusa/ fuga.

A quarta pergunta considera o número de pessoas para quem a pessoa contaria sobre a situação ocorrida e a última pergunta se refere sobre o conteúdo do relato das pessoas. Se a pessoa descreve tanto a pessoa quanto a situação que ocorreu, se descreve ou a pessoa ou a situação ou se não fornece nenhuma informação.

As Tabel as 2 e 3 apresentam os dados obtidos nas entrevistas com as seis partici pantes nas situações apropriadas e inapropriadas, respectivamente:

Tabela 2 - Respostas adequadas (+) e inadequadas (-) obtidas nas situações apropriadas (I,II e VI)

\begin{tabular}{|c|c|c|c|c|c|c|}
\hline Situações Apropriadas & P1 & $\mathbf{P 2}$ & $\mathbf{P 3}$ & $\mathbf{P 4}$ & P5 & P6 \\
\hline $\begin{array}{l}\text { I- após queda de bicicleta, estaria tudo bem seus pais olharem suas } \\
\text { partes íntimas? }\end{array}$ & + & + & + & + & + & + \\
\hline $\begin{array}{l}\text { II -após queda de bicicleta, estaria tudo bem o médico olhar suas } \\
\text { partes íntimas? }\end{array}$ & + & + & + & + & + & - \\
\hline $\begin{array}{l}\text { VI-se suas partes íntimas estivessem machucadas, estaria tudo bem a } \\
\text { enfermeira tocá-las? }\end{array}$ & + & + & + & + & + & + \\
\hline
\end{tabular}


Tabela 3 - Respostas adequadas (+) e inadequadas (-) obtidas nas situações inapropriadas (III, IV e V)

\begin{tabular}{|c|c|c|c|c|c|c|}
\hline $\begin{array}{c}\text { Situações } \\
\text { Inapropriadas }\end{array}$ & P1 & $\mathbf{P 2}$ & $\mathbf{P 3}$ & $\mathbf{P 4}$ & P5 & P6 \\
\hline $\begin{array}{l}\text { III- estaria tudo bem o } \\
\text { vizinho tirar fotos de } \\
\text { suas partes íntimas? }\end{array}$ & + & + & + & + & + & - \\
\hline $\begin{array}{l}\text { O que você diria para } \\
\text { seu vizinho? }\end{array}$ & $\begin{array}{c}\text { Recusa } \\
\text { cautelosa }\end{array}$ & Não recusa & $\begin{array}{c}\text { Recusa } \\
\text { cautelosa }\end{array}$ & $\begin{array}{c}\text { Recusa } \\
\text { definitiva }\end{array}$ & Não recusa & - \\
\hline O que você faria? & $\begin{array}{c}\text { Recusa/fuga } \\
\text { definitiva }\end{array}$ & $\begin{array}{c}\text { Não } \\
\text { recusa/fuga }\end{array}$ & $\begin{array}{c}\text { Recusa/fuga } \\
\text { definitiva }\end{array}$ & $\begin{array}{c}\text { Não } \\
\text { recusa/fuga }\end{array}$ & $\begin{array}{c}\text { Não } \\
\text { respondeu }\end{array}$ & - \\
\hline $\begin{array}{l}\text { Você contaria para } \\
\text { alguém? }\end{array}$ & 1 pessoa & 1 pessoa & 1 pessoa & 1 pessoa & - & - \\
\hline $\begin{array}{l}\text { O que você diria para } \\
\text { pessoa para quem } \\
\text { contou? }\end{array}$ & $\begin{array}{c}\text { Informação } \\
\text { sobre a Pessoa } \\
\text { e situação }\end{array}$ & $\begin{array}{l}\text { Informação } \\
\text { sobre a Pessoa } \\
\text { e situação }\end{array}$ & $\begin{array}{c}\text { Informação } \\
\text { sobre a } \\
\text { Pessoa e } \\
\text { situação } \\
\end{array}$ & - & - & - \\
\hline $\begin{array}{l}\text { IV- estaria tudo bem } \\
\text { seu cuidador trocar } \\
\text { suas partes íntimas em } \\
\text { troca de recompensa? }\end{array}$ & + & + & - & + & + & - \\
\hline $\begin{array}{l}\text { O que você diria para } \\
\text { seu cuidador? }\end{array}$ & $\begin{array}{c}\text { Recusa } \\
\text { cautelosa }\end{array}$ & Não recusa & - & $\begin{array}{c}\text { Recusa } \\
\text { definitiva }\end{array}$ & Não recusa & - \\
\hline O que você faria? & $\begin{array}{c}\text { Não } \\
\text { recusa/fuga }\end{array}$ & $\begin{array}{c}\text { Recusa/fuga } \\
\text { definitiva }\end{array}$ & - & $\begin{array}{c}\text { Recusa/fuga } \\
\text { definitiva }\end{array}$ & - & - \\
\hline $\begin{array}{l}\text { Você contaria para } \\
\text { alguém? }\end{array}$ & 1 pessoa & 1 pessoa & - & 1 pessoa & - & - \\
\hline $\begin{array}{l}\text { O que você diria para } \\
\text { pessoa para quem } \\
\text { contou? }\end{array}$ & $\begin{array}{c}\text { Informação } \\
\text { sobre a pessoa } \\
\text { e situação }\end{array}$ & - & - & - & - & - \\
\hline $\begin{array}{l}\text { V- estaria tudo bem } \\
\text { um homem lhe tocar as } \\
\text { partes intimas em } \\
\text { troca de um sorvete? }\end{array}$ & + & + & + & + & + & + \\
\hline $\begin{array}{l}\text { O que você diria para } \\
\text { esse homem? }\end{array}$ & $\begin{array}{c}\text { Recusa } \\
\text { Definitiva }\end{array}$ & Não recusa & $\begin{array}{c}\text { Recusa } \\
\text { Definitiva }\end{array}$ & $\begin{array}{c}\text { Recusa } \\
\text { cautelosa }\end{array}$ & $\begin{array}{c}\text { Recusa } \\
\text { cautelosa }\end{array}$ & $\begin{array}{c}\text { Recusa } \\
\text { Definiti } \\
\text { va }\end{array}$ \\
\hline O que você faria? & $\begin{array}{c}\text { Não } \\
\text { recusa/fuga }\end{array}$ & $\begin{array}{l}\text { Recusa/fuga } \\
\text { vaga }\end{array}$ & $\begin{array}{l}\text { Recusa/fuga } \\
\text { vaga }\end{array}$ & $\begin{array}{c}\text { Não } \\
\text { recusa/fuga }\end{array}$ & - & - \\
\hline $\begin{array}{l}\text { Você contaria para } \\
\text { alguém? }\end{array}$ & - & 1 pessoa & 1 pessoa & 1 pessoa & - & - \\
\hline $\begin{array}{l}\text { O que você diria para } \\
\text { pessoa para quem } \\
\text { contou? }\end{array}$ & - & $\begin{array}{c}\text { Informação } \\
\text { sobre a pessoa } \\
\text { e situação }\end{array}$ & $\begin{array}{c}\text { Informação } \\
\text { sobre a } \\
\text { pessoa e } \\
\text { situação }\end{array}$ & - & - & - \\
\hline
\end{tabular}


A situação I era considerada apropriada. Todas as participantes responderam sim e ganharam um ponto, ou seja, el as disseram que estaria tudo bem seus pais olharem suas partes íntimas se elas tivessem caído de bicicleta e se machucado. Pode-se dizer que as participantes foram capazes de discriminar que esta é uma situação apropriada, e que não havia problemas em seus pais olharem suas partes íntimas se essas estiverem machucadas. Como as seis participantes responderam adequadamente, não foi necessário fazer as outras perguntas.

A situação II também é considerada uma situação apropriada. Dentre as participantes, cinco (P1, P2, P3, P4, P5) responderam sim, enquanto apenas uma (P6) respondeu que não estaria tudo bem o médico tocasse suas partes íntimas, concluindo-se que a maioria foi capaz de discriminar que essa era uma situação apropriada.

Na situação III, uma situação inapropriada, dentreas seis participantes, cinco (P1, P2, P3, P4, P5) responderam que não estaria tudo bem um vizinho tirar fotos de suas partes íntimas. Tais dados demonstram que as participantes foram, no geral , capazes de discriminar a apropriação de uma situação, nesse caso a não apropriação. A penas uma participante (P6) respondeu que estaria tudo bem o vizinho tirasse fotos de suas partes íntimas.

Ainda em relação à situação III, perguntou-se às cinco participantes “o que você diria" para o vizinho nessa situação. Uma participante (P4) apresentaria recusa definitiva, duas participantes (P1, P3) deram como resposta uma recusa cautelosa, isto é, recusaram o pedido com desculpas ou adiamentos, e duas participantes não recusaram (P2, P5). Diante da pergunta "o que vocêfaria", duas participantes (P1, P3) deram respostas de que recusariam e apresentariam fuga definitiva (retirar-se-iam imediatamente da situação), duas participantes (P4, P2) deram respostas que não recusariam e não apresentariam fuga (permaneceriam na situação, dando apenas uma resposta verbal) e uma participante (P5) não respondeu. Quando perguntadas para quem contariam quatro participantes (P1, $P 2, P 3, P 4)$ disseram que contariam para uma pessoa e dessas quatro, três ( $P 1, P 2$, P3) contariam sobre o vizinho e a situação ocorrida e uma participante (P4) não daria informações precisas sobre o que aconteceu.

Outra situação inapropriada é a situação IV. Quatro participantes (P1, P2, P4, P5) discriminaram que essa seria uma situação inapropriada e disseram que não estaria tudo bem se tocassem nas partes íntimas de seus cuidadores. Duas participantes $(\mathrm{P} 3, \mathrm{P} 6)$ responderam que estaria tudo bem.

Dentre as quatro participantes que responderam não na situação IV , uma deu uma recusa definitiva (P4), uma (P1) deu como resposta uma recusa cautelosa (recusaram com adiamentos ou desculpas) e duas participantes não recusaram (P2, P5). Em relação à pergunta "o que faria" duas participantes (P2, P4) recusariam e sairiam da situação, uma participante (P1) não recusaria e não apresentaria fuga diante da situação e uma participante não respondeu (P5). Três delas (P1, P2, P4) responderam que contariam o ocorrido para uma pessoa, enesses 
relatos uma participante (P1), forneceria informações tanto sobre a pessoa quanto sobre a situação ocorrida e duas participantes (P2, P4) não forneceriam tais informações.

$\mathrm{Na}$ situação $\mathrm{V}$ todas as participantes reconhecerem a inapropriação da situação e responderam que não estaria tudo bem esse homem fazêlo. Dentre todas que responderam não na primeira pergunta da situação $V$, três participantes $(\mathrm{P} 1, \mathrm{P} 3, \mathrm{P} 6)$ recusariam definitivamente, duas (P4, P5) recusariam cautelosamente e uma participante (P2) não recusaria. Em relação à pergunta "o que você faria", duas participantes (P2, P3) recusariam e apresentariam fuga vaga, ou seja, não interromperiam imediatamente a situação, duas participantes (P1, P4) não apresentariam recusa e fuga definitivas e uma participante (P6) não respondeu. Três participantes (P2, P3, P4) contariam o acontecido para uma pessoa e uma participante (P1) não contaria para ninguém. Das participantes que disseram que contariam, duas (P2, P3) forneceriam informações sobre a situação e sobrea pessoa e uma (P4) não forneceria informações precisas.

Finalmente, a sexta situação sendo considerada uma situação apropriada. Todas as participantes responderam sim, ou seja, que estaria tudo bem a enfermeira, que ajuda o médico, tocasse suas partes intimas se estivessem machucadas e com muita dor.

\section{Dıscussão}

Devido ao estigma que carregam, as pessoas com deficiência mental têm geralmente negados seus direitos de expressão sexual e oportunidades de interação social. Elas são muitas vezes tidas como pessoas assexuadas, sexual mente incompetentes ou pessoas com libido incontrolável e hábitos sexuais perversos (ABRAMSON; BURT; LUDLOW apud TAN G; LEE, 1999). Estudos comprovam que o conhecimento sobre sexual idade dos indivíduos com atraso mental é menor em relação aos sem atraso (HALL; M CCABE; WATSON apud TANG; LEE, 1999), eesse éum dos fatores que tornam tais pessoas mais prováveis de vitimização.

Muitas vezes, a população de pessoas diagnosticadas com deficiência mental desconhecee não entendeo queéabuso, edaí a importância de informá-la eajudá-la a discriminar situações das quais poderiam ser vítima. As conseqüências do abuso sexual são graves e abarcam desde sintomas físicos como lesões, hematomas, doenças sexual mentetransmissíveis, etc, como dificuldadeem manter relações amorosas e promiscuidade (RODRIGUES; BRINO; WILLIAMS, 2006). Assim, éimportantealertar as pessoas diagnosticadas com deficiência mental sobre os riscos da violência sexual, orientá-los no sentido quetal fato écrimeeo agressor deve ser punido. Além disso, é imprescindível prepará-los para que possam se proteger diante de situações de risco. 
O presente estudo pretendeu caracterizar o repertório de habilidades de auto proteção de seis mulheres com deficiência mental, no que se refere ao abuso sexual. Com base nos dados obtidos por meio do WIST, pode-se concluir que as mulheres com deficiência mental deste estudo apresentam um déficit em seu repertório dehabilidades de auto proteção, segundo o resultado do instrumento utilizado.

Conforme mostram os resultados, as participantes desteestudo foram capazes de discriminar as situações apropriadas das inapropriadas, o queébastante positivo, porém insuficiente para que elas sejam capazes de se protegerem diante de uma situação potencialmente abusiva do ponto de vista sexual. Os resultados mostraram que elas não apresentavam habilidades necessárias para recusar e sair de situações potencialmente abusivas e ainda, faltavam-Ihes as habilidades necessárias para que pudessem recorrer a uma outra pessoa e contar o que acontecera. Se ao responderem as perguntas da entrevista as participantes mostraram quenão se retirariam da cena em situações hipotéticas, podeser inferido que elas não se retirariam da situação em casos reais.

Os resultados deste estudo corroboram com Brown et al. (1998), que apresentam variáveis de risco para ocorrência do abuso sexual. N esse estudo as variáveis são os participantes serem pessoas do sexo feminino, com deficiência mental.

A lém disso, em relação ao que diz a literatura e o que foi obtido nesse estudo, os resultados estão de acordo com o que foi proposto por Wolfe (1998), ou seja, a importância de serem feitos programas de intervenção com o objetivo de prevenção primária do abuso sexual, ou seja, programas que previnam o abuso de ocorrer. Considerando-se a importância dos processos de prevenção, e considerando-se que a literatura ainda é escassa no que se refere à prevenção do abuso sexual entre as pessoas com deficiência mental, pode-se concluir que há necessidade de estudos mais aprofundados. Inclusive, é preciso verificar se é possível capacitar tais pessoas, de maneira queelas sejam capazes de se protegerem efetivamente diante de situações potencial mente abusivas.

Ainda, considerando-se a importância de estudos preventivos, principalmente no que se refere ao abuso sexual, é rel evante que o repertório de pessoas do sexo masculino, que apresentem atraso de desenvolvimento global, seja caracterizado. Assim, aumentam-seas chances de evitar a ocorrência do abuso sexual dentre todas as pessoas que apresentam deficiência mental, independentemente de gênero.

A pesar de ser um assunto que vêm sendo cada vez mais abordado na mídia, ainda é difícil falar sobre uma questão delicada como o abuso sexual. A sexualidade de pessoas com deficiência mental é comumente considerada pelo senso comum um tabu, tornando-se ainda mais difícil de se abordar o assunto. Entretanto, a grandemaioria das pessoas com deficiência mental chega à puberdade 
e tem a maturação sexual, da mesma maneira que as pessoas sem deficiência (BASTOS; DESLANDES, 2005).

Essa falta de diálogo com a pessoa com deficiência mental pode ser prejudicial não apenas na questão moral de privação de seus direitos, mas pode ser perigoso que uma pessoa não saiba distinguir entre condutas adequadas e inadequadas, sobre sua capacidade de escol her ter relações ou não. Não setrata de despertar essas pessoas para a vida sexual, mas sim ensiná-las informações básicas sobre o que acontece com seu corpo quelhes faz sentir desejo, o queéa masturbação e porque isso Ihe dá prazer, falar sobre as possibilidades de gravidez, sobre as doenças sexualmente transmissíveis, etc.

Assim, a orientação sexual acaba sendo não apenas uma maneira de educá-los para a prática sexual, caso haja o desejo e consentimento, mas é uma forma de prevenção de possíveis situações de abuso sexual, em que não há o desejo e talvez até não haja consciência sobre a situação de abuso que a pessoa com deficiência pode se encontrar.

Além disso, uma pesquisa com tal população eo presente estudo, com tal população, apresenta al gumas dificuldades. Uma das principais dificuldades é obter um relato de uma pessoa com deficiência mental. A pesar das entrevistas terem sido realizadas com seis dentre as 7 mulheres participantes, uma delas, por exemplo, estava agitada e se recusou a permanecer na sala para a realização da entrevista. Houve também situações em que as participantes não responderam al gumas perguntas, e participantes que apresentaram respostas que não tinham relação com o que lhes foi perguntado. Tais dados indicam quedados como histórico prévio de abuso, a dificuldade do instrumento ea dificuldade do tema devem ser mais bem estudados eque devem ser pesquisadas diferentes estratégias para obter relatos, por exemplo, com essa população.

Pode-se concluir então que, apesar do número restrito de participantes desse estudo, as informações obti das apontam para que seja dada maior atenção à prevenção de abuso sexual na população com deficiência mental. Dessa maneira, essas pessoas poderiam receber a ajuda necessária para que, diante de situações potencialmenteabusivas, fossem capazes de se proteger e não sofrer abuso sexual. Sendo assim, essa população terá seus direitos garantidos e suas chances deterem uma vida mais saudável e plena. 


\section{REFERÊNCIAS}

ABRA PIA . A buso Sexual contra crianças e A dolescentes. [revisão eatualização Lauro Monteiro Filho; projeto gráfico eilustrações Gian Calvi] 3. ed. Petrópolis: Editora Autores; A gentes; A ssociados, 2002.

AMAZARRAY, M .R.; KOLLER, S.H. A Iguns aspectos observados no desenvolvimento de crianças vítimas de abuso sexual. R evista de Psicologia R eflexão e Crítica, v.11, n. 3, p. 546-555, 1998.

AMMERMAN, R.T.; VAN HASSELT, V.B.; HERSEN, M .. Maltreatment of handicapped children: A critical review. J ournal of Family Violence, v.1, n. 3, p. 53-72, 1988.

BASTOS, O. M.; DESLANDES, S. F. Sexualidadee o adolescentecom deficiência mental: uma revisão bibliográfica. Ciência \& Saúde Coletiva. Rio de Janeiro, v. 10, n. 2, 2005.

BLANCHARD, J. Sexual exploitation. In: CON GRESSO A GAIN ST THE SEXUAL EXPLOITATION OF CHILDREN, Brasília, 1996.

BRAUN , S. A violência sexual infantil na família: do silencio à revelação do segredo. Porto Alegre: Age, 2002.

BRINO, R.F.; WILLIAMS, L.C.A. Levantamento dos casos notificados deabuso sexual infantil no município de São Carlos. In: REUNIÃO ANUAL DA SOCIEDADE BRASILEIRA DE PSICOLOGIA, 33, Belo Horizonte, 2003. R esumos... Belo Horizonte, 2003.

BROWN, J. et al. A Longitufinal analysis of risk factors for child maltreatment. Findings of a 17 year prospective study of officially recorded and self-reported child abuse and neglect. Child A buse and N eglect, v. 22, n. 11, p. 1065-1078, 1998.

CAMINHA, R. M. Maus tratos: o flagelo da infância. In. BEMVENUTI, V.L. (Org) Caderno de Extensão U N ISIN OS II, p. 37-51, 2000.

CLOITRE, M . et al. Skills training in affective and interpersonal regulation followed by exposure : a phasebased treatment for PTSD related to childhood abuse. Journal of Consulting and Clinical Psychology, v. 70, n. 5, p.1067-1074, 2002.

COHEN, J.A .; MAN NARIN O, A .P. Predictors of treatment outcome in sexually abused children. Child A buse and N eglect, v.24, n.7, p.983-994, 2000.

DREZETT, J. Aspectos biopsicossociais da violência sexual. Jornal da R ede Saúde, p. 1821, 2000.

GABEL, M. Crianças vítimas de abuso sexual. São Paulo: Summus Editorial, 1997.

HABIGZANG, L. F.; CAMINHA, R. M. A buso sexual contra crianças eadolescentes: conceituação e intervenção clínica. São Paulo: Casa do Psi cólogo, 2004.

HAYDE, C., BENTOVIM , A.; M ONCK, E. Someclinical and methodological implications of a treatment outcome study of sexually abused children. Child abuse \& N eglect, v. 19, n. 11, p. 1387-1399, 1995.

HERBERT, M. et al. Proximate effects of a child sexual abuse prevention program in elementray school children. Child A buse \& N eglect, v. 25, n. 4, p. 505-522, 2001. 
KAPLAN . H.I., SADOCK, B. J.; GREBB, J. A. Compên dio de psiquiatria: ciências do comportamento e psiquiatria clínica. 7. ed. Porto Alegre: A rtes Médicas, 1997.

LUM LEY, V. et al. Evaluation of a sexual prevention program for adults with mental retardation. Journal of A pplied Behavior A nalysis, v. 31, n. 1, p. 91-101, 1998.

LUMLEY, V.; MILTENBERGER, R. Sexual A buse prevention for persons with mental retardation. A merican Journal on M ental Retardation, v. 101, p. 459-472, 1997.

MILTENBERGER, R. G. et al. Training and generalization of sexual abuse prevention skills for women with mental retardation. Journal of A pplied Behavior A nalysis, v. 32, n. 3, p. 385-388, 1999.

MINISTÉRIO DA SAÚDE, Descritores em Ciências da Saúde, Biblioteca Virtual em Saúde, 2007. Disponível em http:/ / decs.bvs.br/ . A cesso em: 18nov. 2007.

MONTONI, R. Caracterização da violência contra pessoas com deficiências no M unicípio deSão Carlos. 2004. Trabal ho de Conclusão de Curso (Graduação em Psicologia) Departamento dePsicologia, UniversidadeFederal deSão Carlos, São Carlos.

PADILHA, M. G. S. A buso sexual contra crianças eadolescentes:consi derações sobre os fatores antecedentes e sua importância na prevenção. In: GHUILA HRDI, H. J. et al. (Org.) Comportamento e cognição: contribuições para a construção da teoria do comportamento. Santo André: ESETec Editores A ssociados, 2002. p. 209-220.

RODRIGUES, J. L.; BRINO, R.F.; WILLIAMS, L.C.A. Concepções de sexual idadeentre adolescentes com esem histórico de violência sexual, Paidéia, Ribeirão Preto, v. 16, n. 34, p.229-240, 2006.

SAFFIOTI, H. I. B. No fio da naval ha: Violência contra crianças e adolescentes no Brasil. In: MADEIRA, F. R. (Org.). Q uem mandou nascer mulher? Estudos sobre criançase adolescentes pobres no Brasil. Rio de Janeiro: Rosa dos Tempos, 1996.

SOBSEY, D. et al. Violence and disability: A $n$ annotated bibliography. Baltimore: Paul H. Brookes Publishing, 1995.

STRICKLER, H.L. Interaction between family violenceand mental retardation. M ental Retardation, v. 39, n. 6, p. 461-471, 2001.

SULLIVAN, P. M.; KNUTSON, J. F. Maltreatment and disabilities: A population-based epidemiological study. Child A buse \& N eglect, v. 24, p.1257-1274, 2000.

TANG, C.S.K.; LEE, Y.K.S. Knowledgeon sexual abuseand self-protection skills: A study on female Chinese adolescents with mild mental retardation. Child A buse \& N eglect, v. 23, .n. 3, p. 269-279, 1999.

WATSON, K. Substitutecare providers: hel ping abused and neglected children. Washington: Nayional Center. Child A buse and N eglect, 1994.

WILLIAMS, L.C.A. A buso sexual infantil. In: GHUILAHRDI, H.J.; QUEIROZ, P.P.; PIN HO, N.B.B.P.; SCOZ A.L. (Org.) Comportamento e cogni ção: contribuições paraa construção da teoria do comportamento. Santo A ndré: ESETec Editores A ssociados, 2002. p. 155-164.

Sobre deficiência e violência: reflexões para uma análise de revisão deárea. Revista Brasileira de Educação Especial. Marília, v. 9, n. 2, p. 141-154, 2003. 
WOLFE, V. V. Child sexual abuse. In: MASH, G.; BA RKLEY, R. (Org.) Treatment of childhood disorders. N ova York: The Guilford Press, 1998. p. 545-597.

WURTELE, S., HUGHES, J., OWENS, J.S. A n examination of the reliability of the "What If SituationTest": a brief report. Journal of Child Sexual A buse. v. 7, n. 1, p.41-52, 1998.

ZAVASCHI, M.L. S.; TELELBOM , M.; GAZAL, C. H; SHANSIS, F. M. A buso sexual na infância: um desafio terapêutico. Revista de Psiquitaria, v. 13, n.3, p. 136-145, 1991. 